\title{
EVALUATION OF EFFECTIVE MANURE DISPOSAL SYSTEMS AND ITS INFLUENCE ON SOIL FERTILITY ${ }^{1}$
}

\author{
Pawel I. Gridnev ${ }^{* a}$, Tamayana T. Gridneva ${ }^{a}$, Julia.Y. Spotaru ${ }^{a}$, Wacław Romaniuk ${ }^{b}$ \\ ${ }^{\text {a }}$ All-Russian Research Institute of Animal Husbandry, Moscow, Russia \\ ${ }^{\mathrm{b}}$ Institute of Technology and Life Sciences, Branch Warsaw, Poland \\ *Corresponding author: e-mail: vniimzh213@list.ru
}

\begin{tabular}{|c|c|}
\hline ARTICLE INFO & ABSTRACT \\
\hline $\begin{array}{l}\text { Article history: } \\
\text { Received: July } 2016 \\
\text { Received in the revised form: } \\
\text { August } 2016 \\
\text { Accepted: September } 2016 \\
\text { Key words: } \\
\text { method of assessing, } \\
\text { environmentally safe system, } \\
\text { effective technical measures }\end{array}$ & $\begin{array}{l}\text { The paper presents main provisions of methodology of manure utiliza- } \\
\text { tion systems evaluation. All costs, starting with the costs related to } \\
\text { manure cleaning in premises to the costs of increasing the biological } \\
\text { yield obtained from its use, including the soil fertility value changes, } \\
\text { were considered. The target function is offered a minimum of complex } \\
\text { costs of entering the required amount of nutrients and organic matter } \\
\text { per unit area for the planned yield. The effective technical solutions of } \\
\text { calculations based on the proposed method include: construction of a } \\
\text { boom conveyor with a hydraulic drive and described performance, } \\
\text { scraper and screw types of conveyors, automatic scraper loading } \\
\text { installation of manure from livestock buildings. The proposed solu- } \\
\text { tions will reduce losses of nutrients by } 50-70 \% \text {, and will allow pro- } \\
\text { duction of } 20 \text { million tons of grain annually. }\end{array}$ \\
\hline
\end{tabular}

\section{Введение}

Для России, как и для всего мира важна проблема создания эффективных систем утилизации навоза, и со временем значимость этой проблемы возрастает. Это связано с рядом причин, которые вызвали за последние 20 лет сокращение площади пашни в России на 20 млн. га. Выведенные из оборота земли зарастают лесом, плодородие почвы из-за сокращения содержания гумуса снижается, длительное хранение навоза приводит к загрязнению окружающей среды.

Суммарная упущенная экономическая выгода не эффективного использования удобрительных ресурсов навоза достигает 165 млрд. рублей, ущерб от потерь гумуса в почвах России в зависимости от их типа оценивается в 81,4-739,2 тыс. руб. га ${ }^{-1}$, (Romaniuk и др., 2012; Ковалев, Гриднев, Гриднева, 2016; Гриднев и Гриднева, 2012; www. knowledge.allbest.ru, 2015; Romaniuk, 2009).

1 "Interdisciplinary research on the improvement of energy efficiency and increase of RES participation in the energy balance of the Polish agriculture”. Agreement no. BIOSTRTEG1/269056/5/NCBR/ 2015 as of 11th August 2015 funded by the National Centre for Research and Development as a part of BIOSTRATEG 1 program 
Плодородие почв - это не только богатство сегодняшнего дня, но и богатство будущего, поэтому необходим механизм материального интереса производителей продукции животноводства в системах утилизации навоза, обеспечивающий рост содержания гумуса в почвах.

В действующих нормативных документах источником возможного дохода от утилизации навоза в виде удобрений является ожидаемая прибавка урожая и реализация дополнительной продукции (биогаз, белковые добавки). Учитывая, что за последние годы цены на продукцию растениеводства изменились значительно меньше чем на: топливо, электроэнергию, технические средства и строительные материалы, хозяйства всех сфер не могут заниматься созданием современных систем утилизации навоза, так как затраты не окупаются реальными доходами.

\section{Методика}

С целью создания механизма объективной оценки утилизации навоза нами предложена методика, учитывающая все затраты, начиная от создания систем уборки навоза из животноводческих помещений до прибавки биологического урожая, а также дополнительной продукции в виде биогаза, белковых добавок и стоимостной оценки изменения плодородия почв (Гриднев и Гриднева, 2014).

Для особенностей природно-климатических зон расположения предприятия по производству продукции животноводства учитываются затраты. А именно: создание технологий утилизации навоза, методы по борьбе с сорняками, приобретение и внесение необходимого количества минеральных удобрений, компенсирующих материалов, ущерб окружающей среде от производства и использования органических удобрений, стоимость биологического урожая и дополнительной продукции, изменения плодородия почв.

В качестве целевой функции модели используется минимум комплексных затрат на внесение необходимого количества питательных элементов и органики на единицу площади под планируемую урожайность.

$$
\mathrm{W}_{\mathrm{k}}=\frac{\sigma_{1}+\sigma_{2}+\sigma_{3}+\sigma_{4}+\sigma_{5}+\sigma_{6}-\sigma_{7}-\sigma_{8}-\sigma_{9}}{S_{k}},
$$

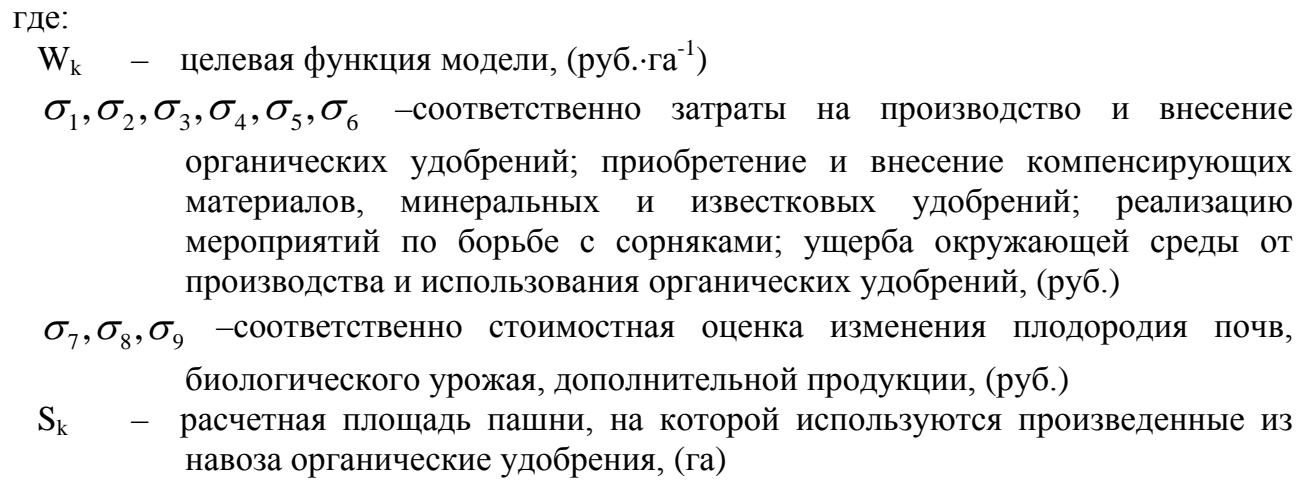


Evaluation of effective...

\section{Анализ}

Анализ зарубежного и отечественного опыта решения проблемы утилизации навоза, результатов теоретических и экспериментальных исследований различных процессов уборки и подготовки навоза к использованию показал, что в ближайшие годы в России следует развивать энергоресурсосберегающие экологически безопасные технологии переработки навоза в высококачественные органические удобрения.

Повысить эффективность системы уборки и подготовки навоза к использованию можно с помощью:

- сокращения количества выполняемых операций по каждой предлагаемой технологии;

- оптимизации места проведения каждой операции и грузопотоков;

- применения принципиально новых способов выполнения операций;

- минимизации количества технологической воды, попадающей в навоз;

- оптимизации конструктивных решений применяемых технических средств.

Экологическую безопасность создаваемых технологий предполагается обеспечить путем:

- минимизации потерь питательных веществ в процессах уборки, хранения и переработки навоза;

- исключения сброса продуктов переработки навоза в водоемы;

- при выборе систем утилизации навоза строго учитывать особенности природноклиматических зон размещения предприятий по производству продукции животноводства;

- применения органических удобрений в регламентированные агрономические сроки;

- точного соблюдение норм внесения органических удобрений.

\section{Результаты}

На основе высказанных соображений и результатов расчета возможных систем утилизации навоза до перспективных технологий и технических средств относятся:

- механические системы транспортирования навоза в животноводческих помещениях;

- производство комплексных органо-минеральных смесей под различные культуры севооборота с заданными физико-механическими и химическими свойствами;

- механическое разделение на фракции жидкого навоза и стоков;

- переработка навоза в анаэробных условиях.

По итогам первого исследования представляется перспективным создание технических средств, работающих на принципах транспортирования навоза к точке выгрузки кратчайшим путем, исключения технологически необоснованного многократного перемешивания, возможность применения автоматизированных систем управления при эксплуатации. Анализ основных технико-экономических показателей механических систем уборки навоза показал, что значительно повысить эффективность процесса можно за счет совершенствования конструкции штангового транспортера и в первую очередь привода тягового контура. В предложенной 
конструкции транспортера привод тягового контура осуществляется от гидравлической станции. Длина рабочего хода плавно изменяется автоматическим реверсом тягового контура. Предложенный транспортер превосходит наиболее часто применяемые технические средства, такие как ТСН-160 и шнековые, соответственно:

- по металлоемкости в 1,8 и 3,0 раза;

- удельной энергоемкости 2,7 и 5,3 раза;

- суточному объему работ по удалению навоза для 100 коров - в 2,0 и 2,3 раза;

- стоимости - в 1,8 и 5,1 раза (Гриднев, Гриднева, Кузьманина, 2015).

В ходе экспериментальных исследований предложенной конструкции штангового транспортера установлено влияние степени заполнения канала навозом на максимально возможную производительность и энергоемкость процесса, предложены зависимости для расчета данных характеристик:

$$
\begin{gathered}
\left\{\begin{array}{l}
M_{1}=-0,104 x^{2}+92,708 x-851,5 \\
M_{2}=-0,558 x^{2}+142,82 x-1899,3 \\
M_{3}=-0,064 x^{2}+69,28 x-546
\end{array}\right. \\
\left\{\begin{array}{l}
Э_{1}=0,0004 x^{2}-0,0648 x+3,055 \\
Э_{2}=0,0004 x^{2}-0,0755 x+3,71 \\
Э_{3}=0,0004 x^{2}-0,071 x+3,145
\end{array}\right.
\end{gathered}
$$

где:

$\mathrm{M}_{1}, \mathrm{M}_{2}, \mathrm{M}_{3}$ - максимально возможная производительность транспортера соответственно при шаге расстановки скребков 0,$5 ; 1,0$ и $1,5 \mathrm{M}, \kappa г \cdot ч^{-1}$

$\mathrm{x}$ - степень заполнения канала навозом, (\%)

$Э_{1}, Э_{2}, Э_{3}-$ удельная энергоемкость процесса уборки навоза соответственно при шаге расстановки скребков 1,$0 ; 0,5 ; 1,5 \mathrm{M},\left(\kappa В \mathrm{~T}^{\cdot} \cdot \mathrm{T}^{-1}\right)$.

Зависимости 2 и 3 справедливы при длине рабочего хода 2,8 м и степени заполнения канала навозом от 25 до 100\%. Максимальная производительность транспортера достигается при шаге расстановки скребков 0,5 м и $100 \%$ степени заполнения канала навозом. Минимальная удельная энергоемкость получена при шаге расстановки скребков 1,0 м, что объясняется меньшей деформацией тела волочения при возврате скребков из рабочего положения в исходное и обратно.

При беспривязном содержании животных возникает необходимость уборки навоза из каналов шириной до 3,5 м. Для механизации данного процесса предложена скреперная установка с гидравлическим приводом и пошаговым перемещением скрепера по длине продольного канала, рис. 1 і 2. От одной гидравлической станции, как и у штангового транспортера, может быть осуществлен привод до четырех контуров. Установленная мощность привода гидростанции 3кВт, длина продольного канала до 150 м, тип тяговой штанги - стальная полоса. Установка работает в автоматическом режиме, что особенно важно для молочных ферм, где возникает необходимость уборки навоза не реже шести раз в сутки. По основным техникоэкономическим показателям установка не уступает лучшим зарубежным аналогам, а 
Evaluation of effective...

по стоимости в 2,0-2,5 раза дешевле, наработка на отказ больше на 15-20\%, материалоемкость меньше на 10-25\%.

Установлено, что потребляемая мощность приводной станции при холостом ходе (гидроцилиндр не работает) составляет 0,506 кВт, при перемещении тягового контура (без перемещения скреперов) - 1,2 КВт. Потребляемая мощность приводной станции при работе скрепера в канале шириной 1,9 м изменяется от 1,25 до 1,44 кВт, в канале шириной 3,4 м - то 1,28 до 1,52 кВт. Изменение влажности убираемого навоза в пределах 92-96\% не оказывает влияния на потребляемую мощность привода. Максимальная производительность скреперной установки при ширине канала 3,4 м и влажности навоза 96\% составляет 4,5 т.ч ${ }^{-1}$, а при ширине канала 1,9 м $3,5 \mathrm{~T} \cdot \mathrm{\varphi}^{-1}$.

При влажности навоза 92\% и расстоянии транспортирования в пределах 50 м максимальная длина тела волочения в канале шириной 3,4 м составляет 3,2 м, а в канале шириной 1,9-2,4 м. При дальнейшем движении навоз перед скрепером уплотняется, длина тела волочения уменьшается, начинается процесс переваливания навоза через скрепер, что приводит к уменьшению показателя полноты уборки и увеличению энергоемкости процесса (Гриднев, Карпов, Гриднева, 2010; Romaniuk и др., 2009).

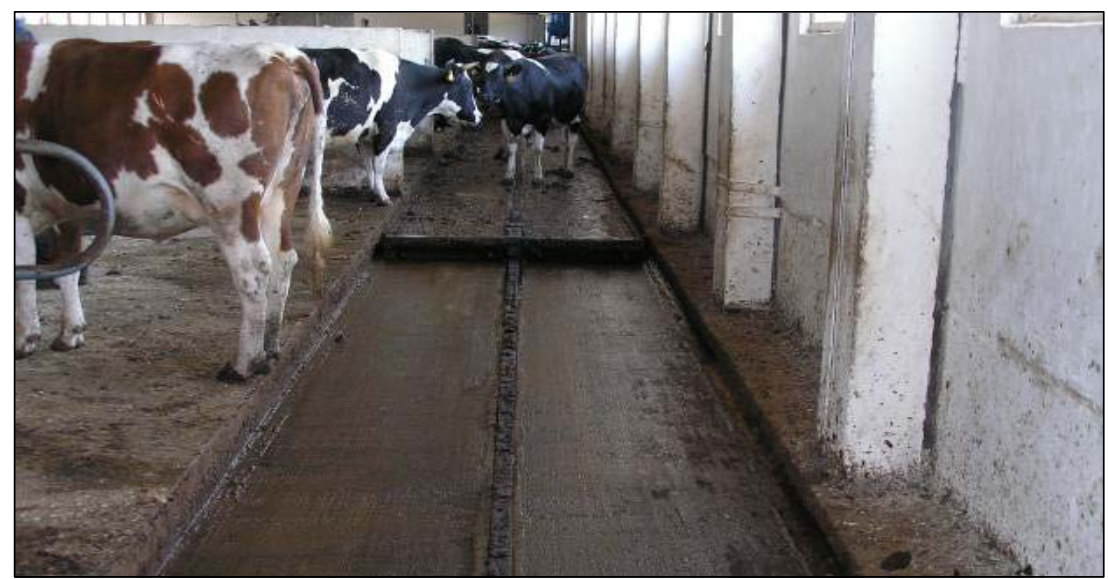

Рисунок 1. Скреперной установки в животноводческом помещении

Из технологий подготовки навоза к использованию наибольший интерес в России, как и во многих странах Европы, представляют: компостирование и механическое разделение на фракции жидкого навоза. Компостированию подвергают подстилочный навоз, удаляемый из помещений механическими средствами, а также твердую фракцию, получаемую в процессе разделения жидкого навоза.

С целью устранения недостатков технологий по производству компостных смесей нами предложено выполнять данную операцию в процессе уборки навоза из помещений (Гриднев и др., 2000), рис. 3. 


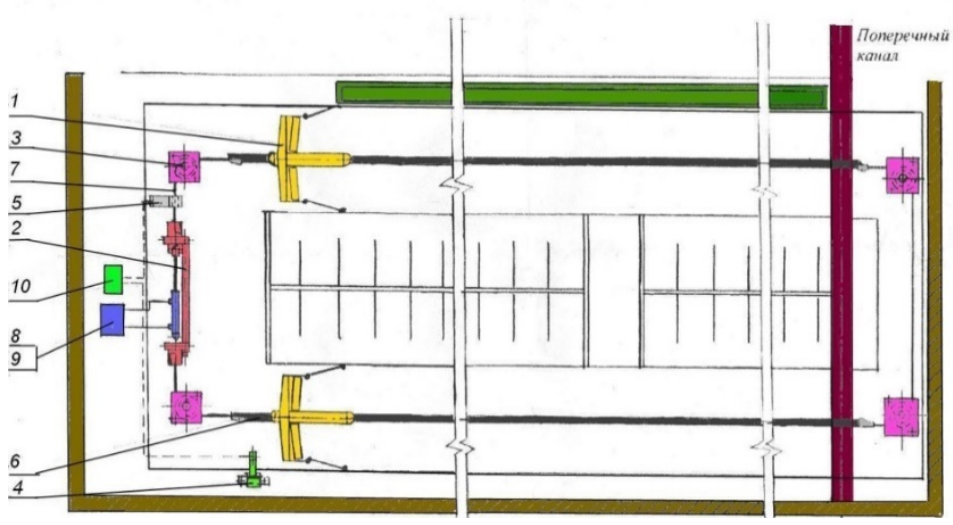

Рисунок 2. Общий вид и схема размещения скреперной установки в животноводческом помещении: 1 - скрепер; 2 - блок поворотный; 3 - канат стальной; 4 - датчик натяжения троса; 5 - станция приводная; 6- шкаф управления; 7 - гидростанция; 8 -магистраль гидравлическая в сборе; 9 - лента; 10 - механизм концевого выключателя

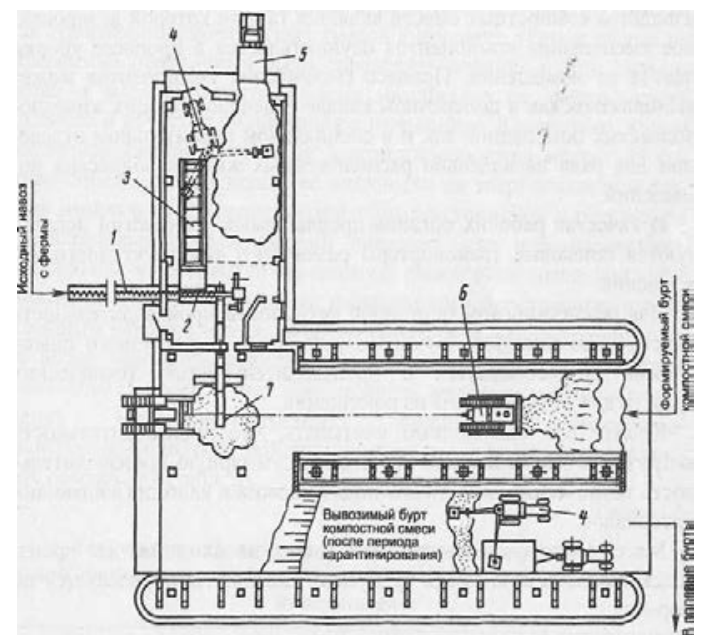

Рисунок 3. Принципиальная схема технологии производства компостных смесей 8 прочессе уборки навоза из помещений: 1 - шнековый транспортер подачи исходного навоза; 2 - транспортер-смеситель инековый; 3 - питатель-дозатор влагопоглощающих материалов; 4 - погрузчик грейферный; 5 - транспорт доставки влагопоглощающих материалов; 6 - бульдозер-буртователь; 7 - наклонный транспортер для выгрузки компостной смеси

При применении данной технологии на выходе из животноводческого помещения обеспечивается круглогодичное производство высококачественных компостных смесей с дозированной подачей компонентов и регулируемым качеством 
Evaluation of effective...

смешивания. При этом более чем в два раза сокращается количество выполняемых операций, исчезает необходимость в строительстве дорогостоящих навозохранилищ, обеспечивается круглогодичное ритмичное производство органических удобрений, на 20-25\% увеличивается количество и улучшается качество производимых удобрений. При проектировании технологий производства компостных смесей необходимо исходить из условий интенсивности протекания процесса биохимического разложения беззольного вещества, а также теплота биохимического окисления должна превышать потери в окружающую среду согласно уравнению теплового баланса для установившегося процесса биохимического окисления беззольного вещества:

$$
\mathrm{Q}_{\text {об }}=\mathrm{Q}_{\sigma}-\mathrm{Q}_{\Pi} \text {, }
$$

где:

$\mathrm{Q}_{\text {об}}, \mathrm{Q}_{\tilde{\sigma}}, \mathrm{Q}_{п}$ - соответственно количество теплоты необходимое для созревания компостной смеси, выделяемое при биохимическом окислении беззольного вещества, теряемое в окружающую среду, (кДж)

Исследованиями (Афанасьев, и др.,1984; Туваев, 1984) установлено, что гарантированное обеззараживание компостных смесей достигается при их разогреве до $70^{\circ} \mathrm{C}$ и выдерживании не менее 72 часов. С учетом этого:

$$
\mathrm{Q}_{\text {об }}=\mathrm{m}_{\mathrm{K}} \cdot \mathrm{C}_{\mathrm{K}}\left(70-\mathrm{t}_{\mathrm{K}}\right) \text {, }
$$

где

$\mathrm{m}_{\mathrm{\kappa}}-$ масса компостной смеси, (кг)

$\mathrm{C}_{\mathrm{\kappa}}-$ теплоемкость комнатной смеси, $\left(\frac{\kappa Д ж}{\kappa 2 \cdot{ }^{\circ} \mathrm{C}}\right)$

$\mathrm{t}_{\mathrm{\kappa}} \quad-$ первоначальная температура компостной смеси, $\left({ }^{\circ} \mathrm{C}\right)$

Количество тепла, выделяемое в процессе биохимического окисления, зависит от массы разложившегося вещества и удельной теплоты окисления:

$$
\mathrm{Q}_{\sigma}=\mathrm{m}_{\sigma} \cdot \mathrm{L} \cdot \mathrm{q},
$$

где

$\mathrm{m}_{\bar{\sigma}} \quad$ - масса беззольного вещества компостной смеси, (кг)

L - требуемая степень распада беззольного вещества, в долях единицы;

q - удельная теплота биохимического разложения беззольного вещества, $\left(\kappa Д ж \cdot \kappa \Gamma^{-1}\right)$

Масса беззольного вещества в компостной смеси состоит из массы беззольного вещества исходного навоза и влагопоглощающего материала:

$$
\mathrm{m}_{6}=\mathrm{Q}_{\mathrm{H}}\left(100-\mathrm{W}_{\mathrm{H}}\right)\left(100-\mathrm{A}_{\mathrm{c}}^{\mathrm{H}}\right) \cdot 10^{-4}+\mathrm{Q}_{\mathrm{B}}\left(100-\mathrm{W}_{\mathrm{B}}\right)\left(100-\mathrm{A}_{\mathrm{C}}^{\mathrm{B}}\right) \cdot 10^{-4},
$$

где:

$\mathrm{Q}_{\mathrm{H}}, \mathrm{Q}_{\mathrm{B}}$ - масса исходного навоза и влагопоглощающего материала, (кг)

$\mathrm{W}_{\mathrm{H}}, \mathrm{W}_{\mathrm{B}}$ - влажность исходного навоза и влагопоглощающего материала, (\%)

$\mathrm{A}_{\mathrm{c}}^{H}, \mathrm{~A}_{\mathrm{c}}^{\varepsilon} \quad$ - зольность исходного навоза и влагопоглощающего материала, (\%) 
Масса требуемого количества влагопоглощающего материала определяется с учетом массы и влажности исходного навоза, влагопоглощающих материалов и компостной смеси:

$$
\mathrm{Q}_{\mathrm{B}}=\frac{\mathrm{Q}_{\mathrm{H}}\left(\mathrm{W}_{\mathrm{H}}-\mathrm{W}_{\mathrm{K}}\right)}{\mathrm{W}_{\mathrm{K}}-\mathrm{W}_{\mathrm{B}}},
$$

где:

$W_{\kappa} \quad$ - влажность компостной смеси, (\%)

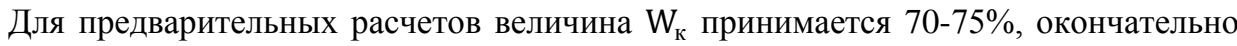
уточняется с учетом уравнения теплового баланса (4).

При гидравлических системах уборки подготовку жидкого навоза и стоков к использованию рекомендуется осуществлять механическим разделением на фракции отечественными фильтрующими центрифугами или установками прессующего типа, (Гриднев и Гриднева, 2015).

Следует отметить, что отечественный комплект оборудования для механического разделения навоза на фракции по сравнению с импортным по стоимости в 3,5-4,3 раза дешевле при сопоставимости затрат на строительство сооружений и эффективности процесса разделения по сухому веществу.

В результате выполненных исследований установлены зависимости для расчета допустимой производительности установки, эффективности разделения по сухому веществу, влажности жидкой и твердой фракций.

Допустимая производительность установки (Q) и эффективность разделения навоза по сухому веществу (Е) при различных диаметрах отверстий фильтрующей перегородки d (от 0,5 до 2,0 мм) при влажности 97,5\%:

для навоза КРС

$$
\begin{aligned}
& Q=-16,66 d^{2}+73,47 d-3,47 \\
& E=-3,49 d^{2}+2,39 d+52,18
\end{aligned}
$$

для свиного навоза

$$
\begin{aligned}
& Q=4,75 d^{2}+42,06 d+24,6 \\
& E=-6,29 d^{2}+1,97 d+55,1
\end{aligned}
$$

Масса твердой фракции $\left(\mathrm{Q}_{\mathrm{T}}\right)$ при механическом разделении навоза на фракции:

$$
\mathrm{Q}_{\mathrm{T \phi}}=\frac{\mathrm{E} \cdot \rho_{\mathrm{u}} \cdot \mathrm{Q}_{\mathrm{u}}\left(100-\mathrm{W}_{\mathrm{u}}\right)}{\mathrm{C}_{\mathrm{T} \phi}},
$$

где:

E - коэффициент эффективности разделения навоза на фракции по сухому веществу, (\%)

$\rho_{u}-$ плотность исходного навоза, $\left(\kappa \Gamma \cdot \mathrm{M}^{-3}\right)$

$Q_{u}$ - объем исходного навоза, $\left(\mathrm{M}^{3}\right)$ 
Evaluation of effective...

$W_{u}$ - влажность исходного навоза, (\%)

$C_{m \phi}$ - содержание сухого вещества в твердой фракции навоза, (\%)

Массу жидкой фракции навоза $\left(\mathrm{Q}_{\text {жф}}\right)$ определяют как разницу между массой исходного навоза и твердой фракции:

$$
\mathrm{Q}_{\text {жф}}=\rho_{\mathrm{u}} \cdot \mathrm{Q}_{\mathrm{u}}-\frac{\mathrm{E} \cdot \rho_{\mathrm{u}} \cdot \mathrm{Q}_{\mathrm{u}}\left(100-\mathrm{W}_{\mathrm{u}}\right)}{\mathrm{C}_{\mathrm{T} \phi}}
$$

\section{Заключение}

Предложенные технологические решения по системам уборки и подготовки навоза к использованию, а также теоретические и экспериментальные зависимости. Методика эколого-экономической оценки систем утилизации навоза позволяют для любого типа предприятия по производству продукции животноводства с учетом конкретных природно-климатических условий зоны расположения объекта выбрать эффективные, экологически безопасные системы уборки и подготовки навоза к использованию, обеспечивающие сокращение потерь питательных элементов на 50$70 \%$, повышение эффективности использования удобрений в 1,3-1,7 раза, дополнительное производство зерна в объеме до 20 млн.тонн в год.

\section{Литература}

Афанасьев, В.Н., Цветков, С.А., Туваев, В.Н. и др. (1984). Производство твердых органических удобрений. Методические указания, 48.

Гриднев, П.И. и др. (2000). Повышение эффективности функционирования технических систем подготовки навоза к использованию, М. Росинформагротех, 80.

Гриднев, П.И. Гриднева, Т.Т. (2015). Анализ технического уровня средств уборки и подготовки навоза к использованию, Вестник ВНИИМЖ, № 1(17), 51-57.

Гриднев, П.И., Гриднева, Т.Т. (2014). Экономико-математическая модель экологически безопасных технологических систем утилизации навоза, Механизация и электрификация сельского хозяйства, № 4, 8-11.

Гриднев, П.И., Гриднева, Т.Т. (2012). Основные направления совершенствования технологий и технических средств для уборки навоза из помещений и подготовки его к использованию, Техника и оборудование для села, № 3, 20-25.

Гриднев, П.И., Гриднева, Т.Т., Кузьманина Ю.Ю. (2015). Результаты экспериментальных исследований процесса уборки навоза штанговым транспортером (Монография под ред. проф. докт. Вацлава Романюка) Фаленты-Варшава, 58-61.

Гриднев, П.И., Карпов, В.П., Гриднева, Т.Т. (2010). Автоматизированная скреперная установка для уборки навоза при беспривязном содержании животных, Техника и оборудование для села, № 8, 18-19.

Ковалев, Н.Г., Гриднев, П.И., Гриднева, Т.Т. (2016). Научное обеспечение развития экологически безопасных систем утилизации, Аграрная наука евро-Северо-Востока, № 1(50), 62-69.

Romaniuk, W., Mazur, K., Domasiewicz, T., Wardal, W.J., Biskupska, K. (2012). Kształtowanie warunków środowiskowych w chowie bydła mlecznego - stan istniejący i propozycje przebudowy, Монография, Inżynieria w Rolnictwie, №4, 92.

Romaniuk, W., Domasiewicz, T., Karbowy, A., Wardal, W.J. (2009). Ograniczenie wpływu produkcji zwierzęcej na środowisko. Inżynieria Rolnicza, №1(110), 233-242. 
Romaniuk, W. (2005). Wymagania formalno-prawne w zakresie standardów techniczno technologicznych w produkcji zwierzęce. Inżynieria Rolnicza, №3(63), 23-32.

Туваев, В.Н. (1984). Технологические процессы и требования к комплексам технических средств для механизированного приготовления компостов на животноводческих фермах и птицефабриках, Дис. кнд. техн. наук - Ленинград - Пушкин, 245.

Оценка убытков и размера возмещения за ухудшение качества сельскохозяйственных земель [электронный ресурc] http:/knowledge.allbest.ru (дата обращения: 16.06.2015).

\section{OCENA SKUTECZNYCH SYSTEMÓW DO USUWANIA GNOJOWICY I ICH WPLYW NA ŻYZNOŚĆ GLEBY}

Streszczenie. Artykuł przedstawia główne punkty metodologii oceny systemów do utylizacji gnojowicy. Rozważania objęły wszelkie koszty, od kosztów związanych z oczyszczaniem gnojowicy w budynkach po koszty związane ze zwiększeniem biologicznego plonu uzyskanego w wyniku jego zastosowania, w tym zmiany wartości żyzności gleby. Funkcja celowa otrzymuje minimalną wysokość kosztów całościowych związanych z wprowadzeniem wymaganej ilości składników odżywczych i masy organicznej na jednostkę powierzchni planowanego plonu. Skuteczne rozwiązania techniczne obliczeń w oparciu o proponowane metody obejmują: budowę belkowego podajnika $\mathrm{z}$ napędem hydraulicznym, automatyczna instalacja ładująca gnojowicę z budynków inwentarskich. Proponowane rozwiązania zredukują straty składników odżywczych o 50-70\% i pozwolą na produkcję 20 milionów ton zbóż rocznie.

Słowa kluczowe: metoda oceny, system bezpieczny dla środowiska, skuteczne metody techniczne 